\title{
Psychological readiness of a modern lecturer for distance teaching
}

\author{
G.P. Grigoriev ${ }^{1 *}, A . A$. Beresnev $^{2}$, and O.A. Rudakova ${ }^{3}$ \\ ${ }^{1}$ V.I. Vernadsky Crimean Federal University, Simferopol, Russia \\ ${ }^{2}$ V.I. Vernadsky Crimean Federal University, Simferopol, Russia \\ ${ }^{3}$ V.I. Vernadsky Crimean Federal University, Simferopol, Russia
}

\begin{abstract}
The article presents the results of a survey of lecturers of Humanities and Education Sciences Academy of V. I. Vernadsky Crimean Federal University in Yalta, as well as lecturers of some other higher educational institutions of the Crimea. The main point of the research was to determine the attitude of the lecturers to distance teaching.
\end{abstract}

\section{A problem statement}

The introduction of information technologies into the educational process and the development of distance education is not a new problem. This problem was described in research works of such scientists as O. Medvedeva [1], V. Mikhinkevich [2], V. Pivovarov [3], I. Sertakova [4], T. Kuzmina [5], N.Hr. Alexandrova [6], R. Shuemer [7] and others.

\subsection{The objective of the work}

However, due to the spread of the infectious disease called COVID-19, the problem has become particularly acute. All universities had to organize distance teaching. Due to the limited time resource during the complete transition from full-time education to distant education, a significant number of problems arose, both of technical and psychological kinds. The main loading fell on the academic staff, who had to revise the methods of the work with students radically.

The Institute for Social Analysis and Forecasting of the Russian Academy of Sciences conducted a survey of more than 30 thousand lecturers across the country [8], which accounted for about $15 \%$ of the total academic staff of the Russian higher school. The results of the research illustrated that lecturers were organizationally ready to switch to distance teaching formats, but psychologically did not accept such a sharp gap with traditional full-time training. The skeptical attitude to what was going on due to the peculiarities of the disciplines taught (for example, technical and experimental), and conservative views on the nature of teaching.

\footnotetext{
*Corresponding author: prof-ped.gpa@mail.ru
} 
According to the research, the main threats associated with the transition to a remote format are:

1) students' motivation drop to study;

2) lack of students'skills and abilities to maintain discipline and diligence in distance learning;

3) emotional breakdowns of both students and lecturers;

4) the load increasing on lecturers;

5) the lack of an individual approach in the system of education, depersonalization;

6) inability to control the level of knowledge;

7) restrictions in a number of areas (primarily technical, mathematical) on the remote transfer of knowledge;

8) formalization of educational processes, a tendency to template, unified solutions [8].

\section{Results of the research}

Our research devoted to the problems of distance teaching was conducted on the basis of V.I. Vernadsky Crimean Federal University and other higher educational institutions of the Republic of Crimea during the first term of the academic year 2020-2021, when higher educational institutions switched to distance teaching completely. 83 lecturers took part in the survey. The characteristics of the sampling are presented in Tables 1 and 2.

Table 1. Gender distribution of the surveyed lecturers.

\begin{tabular}{|c|c|}
\hline Gender of respondents & Percentage ratio \\
\hline Male & $19.5 \%$ \\
\hline Female & $80.5 \%$ \\
\hline
\end{tabular}

Table 2. Distribution of the surveyed lecturers according to the age

\begin{tabular}{|c|c|}
\hline The age of the respondents & Percentage ratio \\
\hline Under 30 years old & $12.2 \%$ \\
\hline $31-40$ years old & $25.6 \%$ \\
\hline $41-50$ years old & $25.6 \%$ \\
\hline $51-60$ years old & $17.1 \%$ \\
\hline Over 60 years old & $19.5 \%$ \\
\hline
\end{tabular}

The presented data illustrate that the age of half of the surveyed lecturers is in the range from 31 to 50 years old, young lecturers (under 30 years) $-12.2 \%$, and the lecturers over 60 years old $-19.5 \%$.

The distribution of the surveyed lecturers according to the direction of their professional activities was of special interest (see Table 3).

The majority of the surveyed lecturers can be seen to be representatives of humanities.

The central question of our research was "What is your attitude towards distance teaching in today's version?". 
Table 3. The distribution of the surveyed lecturers according to the direction of their pedagogical activities.

\begin{tabular}{|c|c|}
\hline Direction of professional pedagogical activities & Percentage ratio \\
\hline Psychological and pedagogical & $37.4 \%$ \\
\hline Historical and philological & $25.7 \%$ \\
\hline Economy and tourism & $10.2 \%$ \\
\hline Art and music & $15.9 \%$ \\
\hline Mathematical-computer science & $6.0 \%$ \\
\hline Medical & $1.2 \%$ \\
\hline Agrarian & $1.2 \%$ \\
\hline Technical & $2.4 \%$ \\
\hline
\end{tabular}

The responses of the lecturers of the surveyed higher educational institutions were distributed as follows (Table 4.):

Table 4. The surveyed lecturers' attitude towards distance teaching.

\begin{tabular}{|c|c|}
\hline Lecturers' attitude towards distance teaching & Percentage ratio \\
\hline Very positive & $5.0 \%$ \\
\hline Positive & $32.9 \%$ \\
\hline Neutral & $28.0 \%$ \\
\hline Negative & $25.6 \%$ \\
\hline Extremely negative & $8.5 \%$ \\
\hline
\end{tabular}

$32.9 \%$ - have a positive attitude to this form of training; $28 \%$ - neutral; $25.6 \%$ expressed a negative opinion; $8.5 \%$ - extremely negative attitude and only $5 \%$ estimate this form as very positive.

Among the lecturers having very positive attitude to distance teaching were only $5 \%$.

The surveyed lecturers" answers to the question "What is the reason for your positive attitude to distance teaching?" distributed as follows:

- 47\% noted - "It is possible to provide well-structured material";

- 19\% - "You can make or find good presentations";

- 12\% - "A good lecture can be found on YouTube";

$-12 \%$ - "It becomes possible not to read the text of your lecture, but to put it on the website";

- $10 \%$ - "You can distract yourself "for a moment" without much damage to the educational process".

Besides single and individual answers were offered:

- Safety from the point of view of coronavirus infection spread.

- If a student stays away from the lecture, he can study the material later.

- It is easier to express yourself in writing.

- More time not only to get ready directly for classes, but also for scientific and methodical work, as you do not need to waste time on transport and bringing yourself to the appropriate appearance.

- Students work more actively in practical classes (seminars). 
The surveyed lecturers' answers to the question "What is the reason for your negative attitude to distance teaching?" distributed as follows:

$40 \%$ - noted "There is no direct contact with students, their eyes and faces are not visible";

- 40\% - "In a full-time lecture and in practical class, the lecturer gives a lot of additional material which is not included in the text of the lecture";

- 20\% - "You have to spend much more time getting ready for lectures and practical classes".

Besides single and individual answers were offered:

- Feeling of isolation from the team, restriction of "live" communication with colleagues and students, lack of physical activity. The inability to control the perception of the material by students - I do not trust the answers from the other side of the screen.

- No feedback, no control over mastering the material (Tests can be copied or guessed), poor Internet connection, lost connection, etc.

- No direct contact with the audience - it is impossible to see the reaction to the submitted material.

- The quality of mastering the material is reduced without personal contact, there is no way to manage the audience.

- Psychological fatigue, increased emotional fatigue, total violation of sanitary standards for working with a PC.

- Low motivation of students to study.

It is noteworthy that the negative attitude towards distance teaching on the part of lecturers is mainly due to the lack of direct live contact with students. The second important point is that the transformation of the lecture material to meet the requirements of distance teaching deprives the lecture of important psychological nuances.

The statements that were made by the lecturers individually in addition to the questionnaire questions should also be paid attention to. Distance teaching breaks not only the direct psychological connection between students and the lecturer, but also deprives the lecturers of this connection among themselves in the department team. Such daily communication is a necessary condition for the psychological comfort of the lecturers' personalities and the basis of the socio-psychological climate in the team.

Also important is the claim that some lecturers spend more time getting ready for classes and violate the hygiene standards of working with a computer.

The surveyed lecturers' answers to the question "How do you think distance teaching can be improved?" distributed as follows:

$15 \%$ - "Give lectures only in interactive video mode";

$55 \%$ - "Diversify a distant lecture with moments that are characteristics of a "live lecture";

$30 \%$ - "Conduct practical classes in direct interactive mode".

Besides single and individual answers were offered:

- I don't know! Maybe just cancel it.

- Include the development of distance courses in the workload of the first half of the day, i.e. in the lecturer's card. The high-quality development and publication of distance courses can be a very time-consuming process.

- Provide each lecturer with powerful technical means, fast Internet, pay for electricity, extra time spent at home, and overtime spent on work, as well as pay extra for the intensity of work.

- Leave the classical form of the educational process without changes.

The distance teaching method requires that lecturers and students should have a sufficient level of computer skills, be capable to apply all peculiarities of the platform chosen for training, be capable to organize a video lecture competently. To find out the 
current situation in this area, the lecturers were asked the following question: "How much do you have the technical knowledge and techniques for working in the remote version? ". The lecturers' responses to this question were distributed as follows (see Table 5):

Table 5. Lecturers' technical knowledge and techniques for working in the remote version.

\begin{tabular}{|c|c|}
\hline $\begin{array}{c}\text { The degree of lecturers' professional skills to work } \\
\text { remotely }\end{array}$ & Percentage ratio \\
\hline I am proficient to a large extent, for me this work is a joy & $37.8 \%$ \\
\hline $\begin{array}{l}\text { I am proficient to a large extent, but this work is a burden } \\
\text { for me }\end{array}$ & $35.4 \%$ \\
\hline $\begin{array}{c}\text { I possess a satisfactory degree of proficiency and this work } \\
\text { requires a lot of effort from me }\end{array}$ & $26.8 \%$ \\
\hline
\end{tabular}

The majority of lecturers $(73.2 \%)$ can be seen to have a large degree of technical knowledge and techniques of working in the remote version. However, for one half of them, such work is a pleasure, and for the other half it is a burden. It should also be noted that for a third of lecturers who have a satisfactory command of technical methods, working remotely requires a lot of effort.

The research conducted allows us to draw the following conclusions:

First, the lecturers' attitude to distance teaching is positive in general. The positive attitude is mainly due to the more rational organization of the educational process, as well as some subjective factors.

Secondly, a significant number of lecturers view the current form of distance teaching negatively and even "very negatively". The main reason for the negative attitude of the lecturers to distance teaching is the lack of direct live contact between the subjects of the educational process.

Third, the technical base of distance teaching and its rational use, as well as the level of special training of both students and lecturers for the work in a remote mode, leave much to be desired.

Fourth, as the result of the survey, the problems of distance teaching being already discussed in the scientific literature are more clearly revealed.

For example, T. Kuzmina [5] revealed significant shortcomings of information technologies in distance teaching:

"1. Attempts to use old teaching methods with new technologies - most of the teaching materials developed for traditional learning cannot be automatically transferred to an online or mixed learning system.

2. Significant difficulties that arise for lecturers when combining the natural human need for communication with ICT - the lecturer has to make a lot of effort to ensure that the course developed imitates live communication.

3. Pedagogical problems related to the fact that a "remote student" studying only through ICT, does not have an opportunity to develop the necessary skills that he could develop during lectures and seminars (personal presentation techniques, "live" discussion and control of emotions, etc.).

4. There is still a lack of professionalism in the development of training materials for distance teaching. There is also a need for lecturers' special training to work with new technologies, as not all lecturers can independently master new educational technologies, and without special training, lecturers develop courses of an unsatisfactory quality" [5].

E. Fadeev is concerned about the problem that both students and lecturers drew attention to in our research. This is the problem of the lack of direct contact, both between students and lecturers, and between students themselves. "An important element of the 
teaching process is the feedback from a student to the lecturer and vice versa. In the case of partial distance teaching, it is carried out in the course of face-to-face communication between the lecturer and a student in real time (during the session). When completely remote (without face-to-face communication between the lecturer and a student) using technical means, including those without visual contact, and not always in real time, there appear to be problems of lack of the feedback, and such psychological resources that affect the results as empathy and interaction are excluded from the communication process" [9].

L. Belyaev notes that "in distance education there are also specific socio-psychological problems, in particular: the problem of low emotional saturation of distance courses, the problem of building interpersonal relationships of distance students with each other and with the lecturer. Ways to optimize distance teaching should be sought in the design of the optimal method of communication within the training group" [10].

According to N. Marchuk, the negative psychological aspects of using the virtual world are the following:

"1) the lack of direct emotional, energetic, suggestive contact of students with the lecturer (complicates the process of transferring socio-cultural experience, reduces the charismatic capabilities of educational subjects, has negative effects on group and professional identification of students, educational motivation);

2) mechanistic nature, projecting the laws of the real world on the virtual environment and vice versa (the lecturer should avoid using methods and teaching techniques that are relevant to the real world without taking into account the features of virtual interaction; it is necessary that students should be given instructions on how the skills they use can be transferred from the virtual world to the real world);

3) depersonalization of the subjects of the educational process (the virtual world contributes not only to anonymity, but also to sensory degradation in communication)" [11].

$\mathrm{N}$. Bryantseva draws attention to the fact that in a stressful situation that was caused by the coronavirus pandemic, the cognitive function of students, in particular short-term memory suffers [12].

L. Muzyka, considering the socio-psychological aspects of distance teaching, believes that "TV-technologies, the main advantage of which is the visibility of educational services as an imitation of the "classic" face-to-face lectures and practical classes should be developed. Their main drawback is the need to "embed" transformed training services into a traditional work schedule, the lack of real interactivity, and the multiplicity of paper" [13].

Despite the difficulties and the problems of distance teaching, it can be stated that to date, a fairly large number of scientific researches and publications have been accumulated, allowing to a certain extent to approach the solution of the problems shown above. One of the publications is the book "The Learning Explosion. 9 Rules to Ignite Your Virtual Classrooms" by Matthew Murdoch Treion Muller [14].

Here are some of these rules:

Many experts agree that information during distance teaching (unlike during face-toface training) should be provided to students in small but meaningful "portions" "fragments of knowledge".

Murdoch and Muller put it in the following way, "The first thing you need to change is the amount of the information you give to your students. Don't try to cram everything you've previously taught in class into a virtual training course. In this sense, the online program is significantly different from the program of traditional training under the direct supervision of a lecturer. If you have content for eight hours of face-to-face lectures, this does not mean that you have content for virtual training for the same eight hours. Students who are personally present in the classroom can learn much more than virtual students.

If you face such restrictions, do not despair. You can adapt your course content to virtual classes using two proven methods: summary and 1 splitting” [14]. 
"Splitting is the division of a large amount of information (for example, of one topic) into small parts - separate semantic blocks. The total amount of information does not change. It means that the number of classes will turn more, only they will turn shorter. Although the splitting makes you spend more time and do it more often, it has an advantage: you can add more illustrations, examples, exercises between the parts (blocks) of information, so that children understand the topic being studied better, get higher marks and it increases their learning motivation" [14].

Another method for forming fragments of knowledge is summarizing. "The aim of the method is to highlight the very essence, the most important points in a voluminous topic. Teaching is conducted in such a way as to focus the students' attention on the basic principles, patterns, and skills. It is the information that is provided to them in small"portions" [11].

Murdock M. and Muller T. propose a 10-step scheme for preparing distance classes (I. Savchenko changed it to take into account the peculiarities of national education [11]).

"Step 1. Determine which "full-time" topic you want to transform into a virtual one.

Step 2. Find out what materials of the original topic you already have (for example, diagrams, PowerPoint slides, tutorial, videos, etc.).

Step 3. Choose which approach to content processing is closer to you: summary or splitting.

Step 4. Make a list of virtual learning tools available from your chosen platform (What do you plan to use? Zoom? MS Teams? Webinar.ru? etc.)

For example: chats, surveys, whiteboard, group discussion, grading, emoticons, screen sharing, etc.

Step 5. Correlate your virtual lesson plan with the available platform features, your method of changing the content, and the best examples of training program design.

Step 6. Adapt the materials of the existing traditional (full-time) course to the needs of your virtual lesson.

Step 7. Analyze the resulting sample of the lesson and make the necessary changes.

Step 8. Test the lesson on a trial audience (for example, on your own family members).

Step 9. Get and analyze the feedback.

Step 10. Continue testing and receiving the feedback until you feel that your lesson is ready to use." [15].

Improving the effectiveness of distance teaching can be achieved on the basis of the following principles:

Table 6. Some recommendations for organizing distance teaching [15].

\begin{tabular}{|c|c|}
\hline Bad & Good \\
\hline $\begin{array}{l}\text { Just give a lecture. } \\
\text { Use PowerPoint only. } \\
\text { Improvise. } \\
\text { Allow questions to be asked only in the end } \\
\text { Expect everything to happen "as usual". } \\
\text { Do the same thing every time. } \\
\text { Fully rely on a certain specialist who will } \\
\text { manage the platform. } \\
\text { Do the same thing every time. }\end{array}$ & $\begin{array}{l}\text { Plan frequent interactive. } \\
\text { Use different forms of visual presentation of } \\
\text { the material. } \\
\text { Practice. } \\
\text { Engage students in verbal communication } \\
\text { (information exchange). } \\
\text { Adapt tasks and exercises to the capabilities of } \\
\text { the platform. } \\
\text { Do not allow participants to do anything. } \\
\text { Get the feedback all the time - listen and then } \\
\text { use it. } \\
\text { Provide students with handouts. } \\
\text { Know the technical capabilities of the platform } \\
\text { used }\end{array}$ \\
\hline
\end{tabular}


The next important principle that must be followed when conducting an online class is its duration. "In our experience, more than two hours is too much, even if the lesson is accompanied by frequent and varied interactive activities. Sessions of 90 to 120 minutes are the ideal duration of a virtual class. During this time, you will be able to present three or four main ideas, and your listeners will not have time to get bored. Of course, we understand that there are different situations. You will have to experiment and work out the ideal ratio of content and duration in your particular case.

It is important to note that the student's ability to absorb information during a single session decreases according to the principle of decreasing effect. When conducting a class, you should feel for this moment to come, and adjust your performance accordingly. You probably know how to do it in a traditional classroom. But online audience, it is much more difficult to determine that it is time to switch and change something." [7].

One of the problems which arises in distance teaching is the problem of compliance with the hygienic standards of working on a computer. Possible solutions to the problem consist in alternating the online form of the lesson (lecture, interactive seminar) with the task using a traditional paper textbook.

As it was stated above, one of the most significant problems of distance teaching is the lack of direct and informal communication between lecturers and students, lecturers and lecturers, as well as students and students.

In our opinion, at least a partial solution to this problem is to create a special group in one of the social networks. So, in our Academy, a special conversation "We are all at home" was created in "In Contact", which immediately became popular with both students and lecturers. The day began with the participants of this conversation saying hello, wishing good morning to everyone, sharing their impressions about the events of their personal and student life, i.e. there was a real informal communication until late in the evening with a break until the next morning. The phenomenon of the conversation popularity is explained by the fact that it was customary for students to communicate in social networks, and it was a surprise to meet their lecturers in the same conversation.

\section{Conclusions}

Thus, it was revealed that $32.9 \%$ have a positive attitude to this format of training; $28 \%$ neutral; $25.6 \%$ expressed a negative opinion; $8.5 \%$ - expressed extremely negative attitude and only $5 \%$ assess this format very positively. Those who have a positive attitude to distance teaching, note the ability to structure the training material well, create or find good presentations for a lecture, as well as reduce the risk of infection. The negative attitude of lecturers to distance teaching is primarily due to the fact that there is no direct contact with students and colleagues, and it is impossible to control the perception of the material by students. To clarify the situation with the lecturers' computer literacy, the following question was asked: "How much do you have technical knowledge and techniques for working in the remote version? ". The majority of lecturers $(73.2 \%)$ have a high degree of technical knowledge and techniques of working remotely. However, for one half of them, such work is a pleasure, and for the other half it is a burden. According to the results of the research, the following conclusions are made. First, the attitude of lecturers to distance teaching is generally positive. Secondly, a significant number of lecturers view the current form of distance teaching negatively and even "very negatively". The main reason for the lecturers' negative attitude to distance teaching is the lack of direct live contact between the subjects of the educational process. The article also presents some methodical approaches with the help of which distance teaching can be improved. In this regard, we can conclude that the rapid introduction of online teaching into the traditional educational process has 
created a number of organizational, technical and psychological problems, which is reflected in the results of the survey of students and lecturers.

At the same time, our research shows that there are currently quite serious opportunities to solve these problems.

\section{References}

1. O.A. Medvedeva, Methodological foundations for the use of information and communication technologies in the process of training future specialists in higher educational institutions, 21-25 (2016)

2. V.V. Mikhinkevich, On the problems of using computer information technologies in the educational process of the university, 226-228 (2016)

3. V.A. Pivovarov, Problematic field of transition of the higher education system to distance learning, 4, 77-80 (2020)

4 I.N. Sertakova, New technologies in the field of education and educational service, [Electronic resource]: http://analiculturolog.ru/component/k2/item/236-article_48.html.

5. T.V. Kuzmina, Student in the E-learning environment, 62 (2008)

6. N.Kh. Alexandrova, The psychological aspects of the distance education, [Electronic resource] https://www.researchgate.net/publication/315790001 (2020)

7. Sch. Rudolf, Some Psychological Aspects of Distance Education, 40 (Fern Univ., Hagen, Germany, 2020)

8. Ministry of Science and Higher Education of the Russian Federation, [Electronic resource]: https://www. minobrnauki.gov.ru/ru/press-center/card/?id_4=2603

9. L.V. Belyaev, On the issue of social and psychological problems of distance learning, Basic research, 1, 19-21 (2005)

10. E.V. Fadeev, Organizational and psychological problems of distance learning, The world of science, culture, education, 3(64), 308-310 (2017)

11. N.Yu. Marchuk, Psychological and pedagogical features of distance learning, 4, 78-85 (2013)

12. N. Bryantseva, Some psychological problems of distance learning in a period of increased stress, Psychological education [Electronic resource]: https://www.b17.ru/article/distance_learning_under-stress/ (2020)

13. L.V. Musica, Socio-psychological aspects of distance learning, Bulletin of Omsk University, 2, 66-68 (2004)

14. M. Murdoch, Learning Explosion: Nine Rules for an Effective Virtual Classroom, 190 (2012)

15. I.A. Savchenko, Psychological aspects of effective distance lesson, [Electronic resource]:

https://eduface.ru/consultation/psiholog/psihologicheskie_aspekty_effektivnogo_distanc ionnogo_uroka 